\title{
Itraconazole Modulates Hedgehog, WNT/ $\beta$-catenin, as well as Akt Signalling, and Inhibits Proliferation of Cervical Cancer Cells
}

\author{
TOMOKO UEDA ${ }^{1}$, HIROSHI TSUBAMOTO ${ }^{1,2}$, KAYO INOUE $^{1}$, KAZUKO SAKATA $^{1}$, \\ HIROAKI SHIBAHARA ${ }^{1}$ and TAKASHI SONODA ${ }^{2}$ \\ ${ }^{1}$ Department of Obstetrics and Gynecology, Hyogo College of Medicine, Nishinomiya, Japan; \\ ${ }^{2}$ Department of Medical Oncology, Meiwa Hospital, Nishinomiya, Japan
}

\begin{abstract}
Background/Aim: Repurposing itraconazole as an anticancer agent has been evaluated in several studies. The present study investigated whether itraconazole exerts an anticancer effect on cervical cancer cells. Materials and Methods: CaSki and HeLa cells were cultured in itraconazole and vehicle after which colony-forming and cell viability assays were performed. Transcription and protein expression were assessed by cDNA microarray analysis and immunoblotting, respectively. Results: Itraconazole suppressed proliferation of CaSki and HeLa cells in a doseand time-dependent manner. Furthermore, CaSki cells were more significantly affected by itraconazole than HeLa cells. The microarray analysis showed an 8-fold down-regulation in the expression of GLII, WNT4 and WNTIOA among itraconazole-treated CaSki cells. Moreover, the transcription of sterol carrier protein-2 and ATP-binding cassette transporter-1 was unaffected by itraconazole. Immunoblots showed suppression in $\beta$-catenin expression and Akt phosphorylation. Conclusion: Itraconazole is a multitargeting anticancer agent and a promising therapeutic agent for cervical cancer.
\end{abstract}

Cervical cancer is caused by persistent infection with human papillomavirus (HPV), particularly the oncogenic subtypes, such as HPV16 and 18. Screening for cervical cancer via Papanicolaou smears or HPV DNA testing and vaccination against the disease were introduced in developed countries, that have resulted in reduced mortality. However, cervical

Correspondence to: Hiroshi Tsubamoto, Department of Obstetrics and Gynecology, Hyogo College of Medicine, 1-1 Mukogawa, Nishinomiya, Hyogo 663-8501, Japan. Tel: +81 798456481, Fax: +81 798464163, e-mail: tsuba@hyo-med.ac.jp

Key Words: Itraconazole, hedgehog, AKT/mTOR, WNT/ß-catenin, cervical cancer. cancer is still a major gynaecologic cancer especially in developing countries. In 2013, 485,000 new cases were diagnosed and 236,000 mortalities occurred worldwide. In addition, more than $85 \%$ of the morbidities and mortalities were recorded in low- and middle-income countries (1). In a randomised trial, bevacizumab, a recombinant humanized monoclonal antibody directed against circulating vascular endothelial growth factor, was found to improve overall survival (OS) among patients with metastatic or recurrent disease. The median OS in the trial was 17 months (2); however, the enrolled patients were in good physical condition. Six percent of the patients who were administered bevacizumab had fistulas of grade 3 or higher, whereas $8 \%$ of the patients had thromboembolism of grade 3 or higher, which might have deteriorated their quality of life. There is, therefore, an urgent need for the development of new treatments for cervical cancer.

Drug repurposing meets the economic and time demands of developing new and safe anticancer agents. Itraconazole is a common antifungal agent that has demonstrated reversal effects on P-glycoprotein-mediated chemoresistance and the suppression of Akt/mechanistic target of rapamycin (mTOR), Hedgehog (Hh) and the WNT/ $\beta$-catenin pathway in various cancer cells. In addition, it has shown effects in the inhibition of angiogenesis and lymphangiogenesis. Survival benefit in cancer patients treated with itraconazole has been proposed in non-small cell lung, ovarian, triplenegative breast, pancreatic and biliary tract cancers (3). Furthermore, itraconazole was found to reverse Pglycoprotein-mediated taxane resistance in HeLa-derived cells (4). It has also been shown that itraconazole alone inhibits proliferation of $\mathrm{HeLa}$ cells at a $50 \%$ growth inhibitory concentration of $5 \mu \mathrm{M}(5)$.

In light of the anti-cancerous properties of itraconazole, we investigated the effects of itraconazole on cervical cancer cells and explored molecular mechanisms underlying the effects. We found that itraconazole suppressed Hh, WNT/ $\beta$ - 
catenin, as well as Akt signalling pathways, and inhibited the proliferation of cervical cancer cells in a dose- and timedependent manner.

\section{Materials and Methods}

Cell culture. Human cervical squamous cell carcinoma cell lines (HeLa, HPV-18+; CaSki, HPV-16+) were obtained from RIKEN BioResource Center (Tsukuba, Japan). The cells were cultured according to the supplier's instructions.

Colony-forming assay. The cells were seeded at a density of $1 \times 10^{3}$ cells/well, cultured in a medium containing a specific concentration of itraconazole for 2 weeks and stained with Giemsa's solution.

Cell viability assay (WST-1). Cells $\left(5 \times 10^{3 /}\right.$ well) were seeded in $96-$ well culture plates and allowed to adhere to the plates overnight. Attached cells were treated with up to $10 \mu \mathrm{M}$ itraconazole (SigmaAldrich, Tokyo, Japan) for 48, 72 or $96 \mathrm{~h}$. Cell viability was evaluated using Premix WST-1 Cell Proliferation Assay System (Takara Bio Inc., Shiga, Japan) according to the manufacturer's instructions. The cells were incubated with WST-1 for an additional $4 \mathrm{~h}$. Dissolved formazan product was evaluated by measuring the absorbances of the samples at 440 and $630 \mathrm{~nm}$ on a microplate reader. Each experiment was repeated at least three times.

Microarray analysis of gene expression. Cells were cultured with $10 \mu \mathrm{M}$ of itraconazole or vehicle for 48 or $96 \mathrm{~h}$ and harvested. RNA was extracted from five paired samples and analysed using SurePrint G3 Human Gene Expression $8 \times 60 \mathrm{~K}$ v2 Microarray kit (Agilent Technologies, Tokyo, Japan). Altered gene expression was calculated as $\log 2$ (mRNA level in itraconazole-treated cells $v s$. mRNA level in vehicle-treated cells), with a difference of more than 4 -fold $\left(\log _{2}\right.$ ratio $>2$ or $\left.<-2\right)$ being considered as a change at the level of transcription.

Immunoblotting. Cell samples were lysed with CelLytic M lysis buffer containing Phosphatase Inhibitor Cocktail 2 and Protease Inhibitor Cocktail. All the reagents were purchased from SigmaAldrich. Proteins $(2 \mu \mathrm{g})$ were size-fractionated by sodium dodecyl sulphate-polyacrylamide gel electrophoresis using $15 \%$ or $5-20 \%$ gel. The proteins were then transferred onto a polyvinylidene difluoride membrane (ATTO, Tokyo, Japan), which was blocked with EzBlock Chemi (ATTO) and incubated with primary antibodies against the following proteins: mTOR, phospho-mTOR, p70 S6 kinase (S6k), phospho-p70S6K (p-S6k), $\beta$-catenin, C-MYC and Akt (each at 1:1,000 dilution; Cell Signalling Technology, Danvers, MA, USA); Wnt4 and Wnt10A (each at 1:1,000 from Abcam, Cambridge, UK); and $\beta$-actin (at 1:1,000 from MBL, Nagoya, Japan). After washing with phosphate-buffered saline containing $0.01 \%$ Tween 20 (Wako Pure Chemical Industries, Osaka, Japan), the blots were probed with secondary antibodies for $1 \mathrm{~h}$ at room temperature. Immunoreactivity was visualised using an ECL Prime Western Blot Detection kit (GE Healthcare Life Sciences, Little Chalfont, UK).

Statistical analysis. The Mann-Whitney $U$-test was used to evaluate differences between two groups using XLSTAT 2014 software (Addinsoft, Paris, France). All $p$-values $<0.05$ were considered statistically significant.

\section{Results}

Itraconazole inhibits cervical cancer cell proliferation. Itraconazole inhibited the proliferation of CaSki and HeLa cells in a dose- and time-dependent manner (Figures 1 and 2). However, after incubation with itraconazole at a concentration of $1 \mu \mathrm{M}$ for $96 \mathrm{~h}$, CaSki cells were more significantly affected than HeLa cells were $(p<0.001$ and $p=0.01$, respectively).

Itraconazole alters the gene expression of the Hh and $W N T / \beta$-catenin pathway proteins. In the absence of itraconazole, the transcription of GLII in CaSki cells was 18fold higher than that in HeLa cells. However, after incubation with $10 \mu \mathrm{M}$ itraconazole for $48 \mathrm{~h}$, there was down-regulation in GLII transcription by 20 -fold (Table I). Moreover, itraconazole caused an 8-fold down-regulation in the transcription of WNT4 and WNT10A and more than a 6fold up-regulation in the expression of WNT inhibitory factor-1 (WIFl) in the CaSki cells (Table II). Sterol carrier protein-2 (SCP2) and ATP-binding cassette transporter-1 $(A B C A 1)$ were unaffected at the transcriptional level by itraconazole in the CaSki or HeLa cells.

Immunoblotting of proteins extracted from CaSki cells after treatment with itraconazole. The expression levels of $\beta$ catenin and C-MYC proteins were suppressed after CaSki cells were incubated with $10 \mu \mathrm{M}$ itraconazole; however, the expression of WNT4 and WNT10A were unchanged. The phosphorylation of Akt was decreased by itraconazole at a concentration of $10 \mu \mathrm{M}$; however, that of mTOR or S6k was not affected (Figure 3).

\section{Discussion}

The Hh signaling pathway involves three ligands: Indian Hh, desert $\mathrm{Hh}$ and sonic $\mathrm{Hh}(\mathrm{sHh})$. Transmembrane protein patched 1 (PTCH1) inhibits the activity of smoothened (SMO). When Hh ligands binds to PTCH1, SMO is activated, which leads to the activation of the translational modulators GLI1, GLI2, and GLI3 (6). Hh signaling is activated at advanced stages of cervical cancer. Moreover, it is associated with carcinogenesis, invasion, metastasis, recurrence and chemoresistance (7-10). It has been reported that, in cervical cancer cells, including HeLa and CaSki cells, there is overexpression of GLI1, PTCH1, SMO and $\mathrm{SHh}$. Moreover, it has been noted that $\mathrm{Hh}$ inhibitors reduce the proliferation and survival of cervical cancer cells (11).

Furthermore, it has been reported that the Hh signaling pathway is up-regulated in basal cell carcinomas (BCCs) of the skin. Additionally, SMO antagonists, such as vismodegib and sonidegib, are recommended for the treatment of advanced and recurrent disease. Itraconazole reduces sHh- 


\section{CaSki Cells}

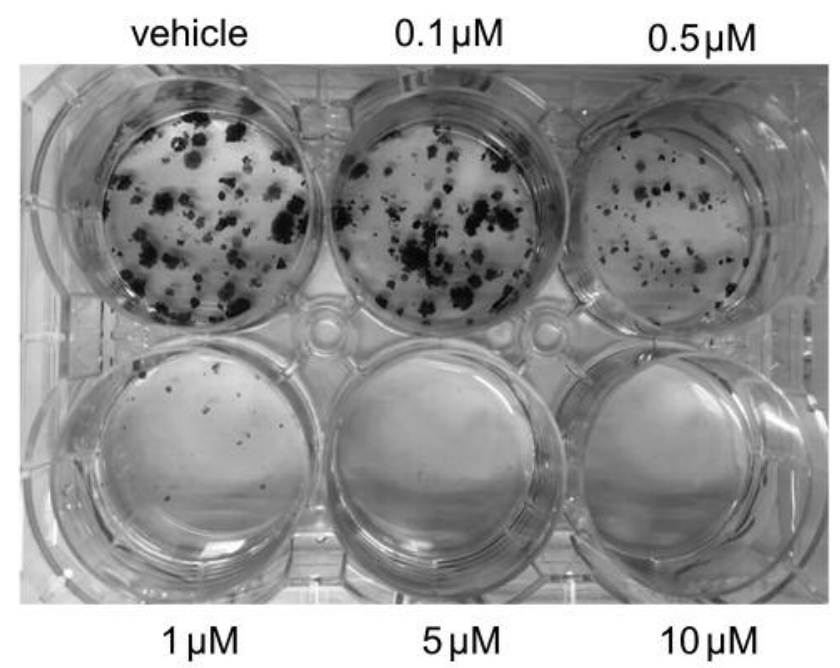

HeLa Cells

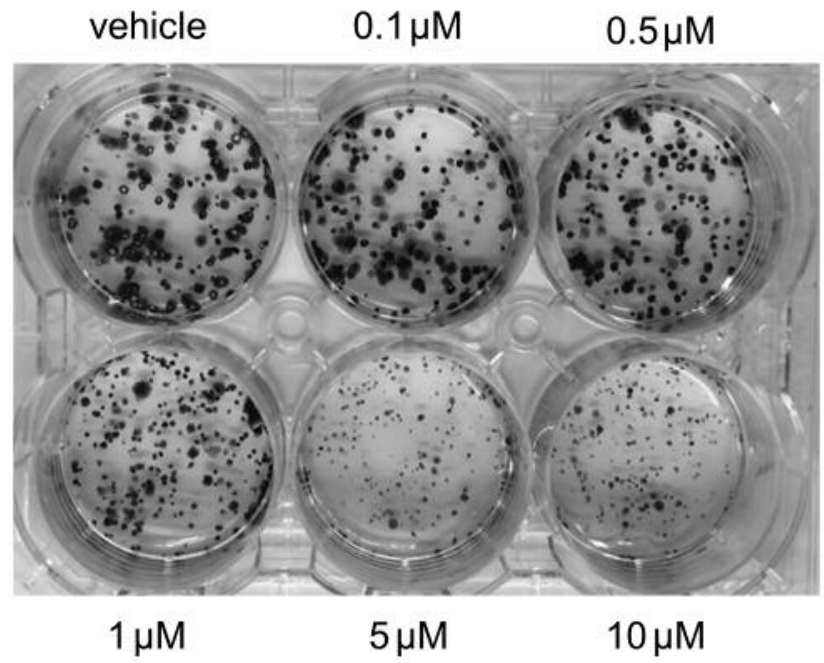

Figure 1. Representative images showing colony formation after incubation with itraconazole for 14 days. CaSki and HeLa cells were seeded at $1 \times 10^{3}$ cells/well, cultured with a medium containing a specific concentration of itraconazole for 2 weeks and stained with Giemsa's solution.

\section{A. Growth Inhibition of CaSki cells}

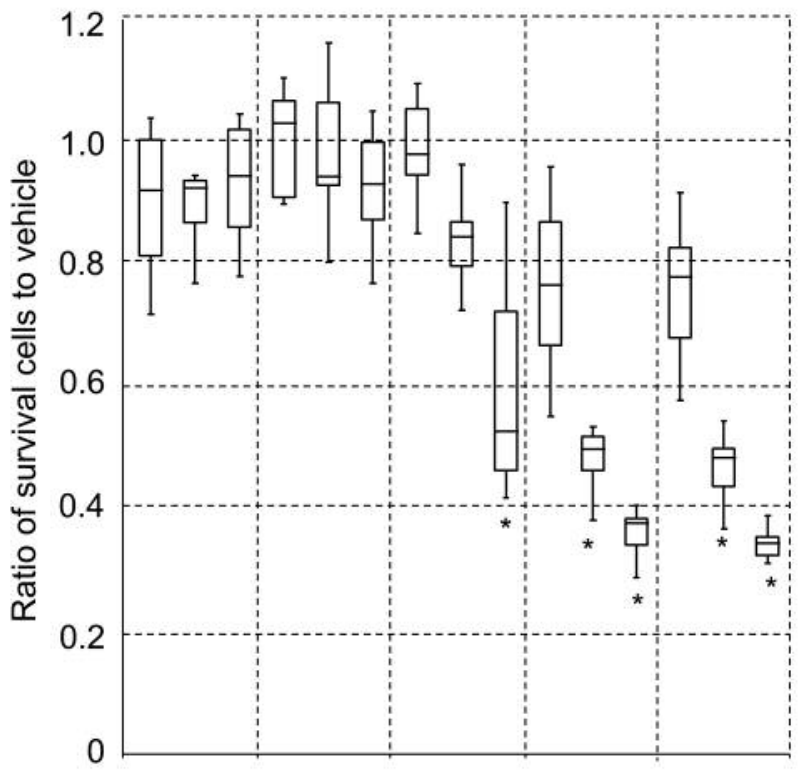

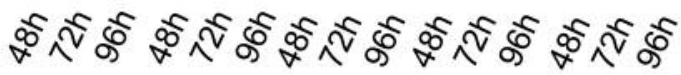

0.1
5

10

Concentration of itra $(\mu \mathrm{M})$

\section{B. Growth Inhibition of HeLa cells}

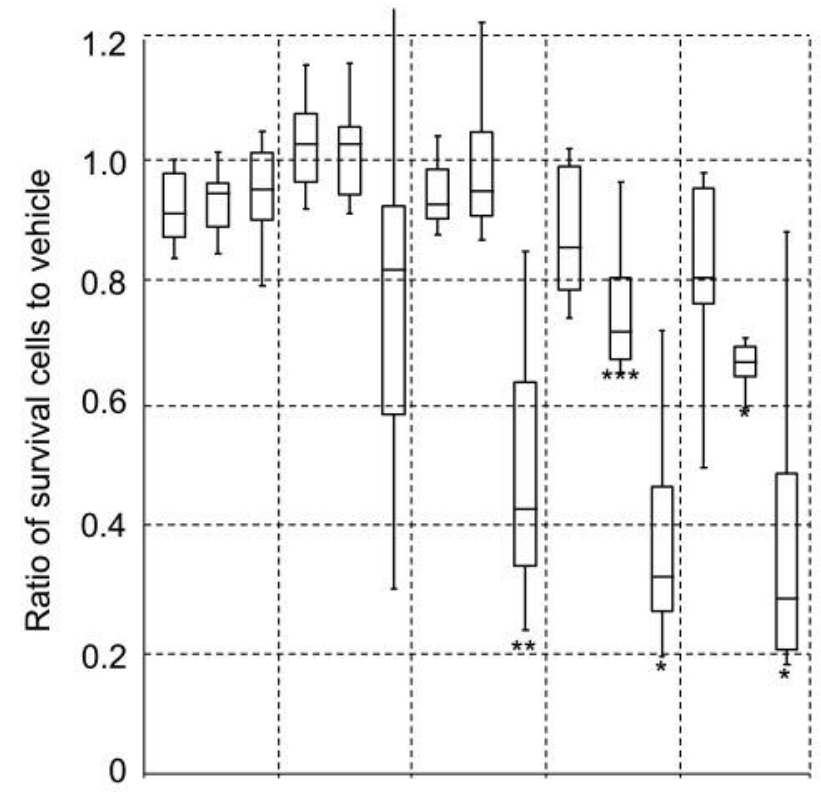

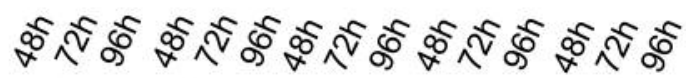

0.5

Concentration of itra $(\mu \mathrm{M})$

Figure 2. Inhibition of cell growth by itraconazole. A cell proliferation WST assay of cervical cancer cells was conducted and the number of surviving cells in each medium containing itraconazole was compared to that in the vehicle. Itra, Itraconazole. Statistical analysis was conducted using the Mann-Whitney U-test. ${ }^{*} p<0.001,{ }^{* *} p<0.01,{ }^{* * *} p<0.04$. 
Table I. cDNA microarray analysis of Hh signalling after treatment with itraconazole.

\begin{tabular}{|c|c|c|c|c|c|c|c|}
\hline \multirow[t]{2}{*}{$\log _{2}$ ratio } & \multicolumn{3}{|c|}{ CaSki/HeLa } & \multicolumn{2}{|c|}{ HeLa } & \multicolumn{2}{|c|}{ CaSki } \\
\hline & Vehicle & $48 \mathrm{~h}$ & $96 \mathrm{~h}$ & $48 \mathrm{~h} /$ vehicle & $96 \mathrm{~h} /$ vehicle & $48 \mathrm{~h} /$ vehicle & $96 \mathrm{~h} /$ vehicle \\
\hline GLI1 & 4.3 & -0.08 & 1.94 & -0.07 & -0.18 & -4.44 & -2.54 \\
\hline GLI2 & -3 & -2.56 & -1.9 & -0.16 & -0.44 & 0.04 & 0.36 \\
\hline GLI3 & -1.98 & -1.23 & -1.84 & -0.46 & -0.39 & 0.3 & -0.25 \\
\hline $\mathrm{sHh}$ & 0.01 & -0.8 & 0.32 & 0.39 & 0.34 & -0.41 & 0.65 \\
\hline $\mathrm{dHh}$ & 3.34 & -0.79 & 2.17 & -0.68 & -0.82 & -4.8 & -1.99 \\
\hline Ihh & 0.31 & 0.9 & 1.91 & -1.45 & -0.71 & -0.85 & 0.89 \\
\hline PTCH2 & 0.21 & 0.3 & 0.21 & 0.1 & 0.63 & 0.26 & 0.23 \\
\hline SMO & -1.13 & 0.2 & -0.85 & -1.18 & 0.24 & 0.15 & 0.52 \\
\hline
\end{tabular}

GLI1 expression was higher in CaSki cells than in HeLa cells. In addition, it was significantly down-regulated by itraconazole in the CaSki cells. The coloured cells indicate $>4$-fold changes in transcription. $\mathrm{dHh}$, Desert hedgehog; GLI, glioma-associated oncogene homolog; iHh, Indian hedgehog; PTCH, patched family hedgehog receptor; sHh, sonic hedgehog; SMO, smoothened.

induced accumulation of SMO in the primary cilium and suppresses the signals (12). Furthermore, treatment with itraconazole was noted to produce clinical response to $\mathrm{BCC}$ in a phase II clinical trial (13). CaSki cells show mutations in sHh (D154E) and PIK3CA (E545K) (14). In the present study, the transcription of GLII was higher in CaSki cells than it was in HeLa cells; however, after treatment with itraconazole, it was at similar levels in the two cell lines.

The phosphoinositide 3-kinase (PI3K)/AKT/mTOR signaling pathway has a critical role in tumour progression. The downstream targets of mTORC1 include eIF4E binding protein 1 and $\mathrm{S} 6 \mathrm{~K}$, which regulate mRNA translation (15). Abnormal activation of mTOR signalling occurs in various human cancers, including cervical cancer $(16,17)$. The Cancer Genome Atlas Research Network has revealed that $26 \%$ and $8 \%$ of squamous cell carcinomas show mutations in in PIK3CA and PTEN, respectively (18). There is only one reported clinical trial that investigated targeting of the $\mathrm{PI} 3 \mathrm{~K} / \mathrm{AKT} / \mathrm{mTOR}$ signaling pathway in cervical cancer. It was a phase II clinical trial in which 38 patients with advanced or recurrent cervical cancer were treated with temsirolimus. The 6-month progression-free survival rate of the patients was 28\%. Additionally, the statuses of PTEN and PIK3CA were studied; however, no correlation between molecular expression signatures and clinical activity of temsirolimus was observed (19). CaSki cells show mutation in PIK3CA (E545E) (14). Moreover, phosphorylation of Akt was decreased by itraconazole; however, the downstream pathway involving mTOR and S6k was not affected by the treatment.

The WNT/ $\beta$-catenin signalling pathway includes canonical and non-canonical pathways, which are activated by the Frizzled family of receptors and a co-receptor (LRP5/6). The canonical signal activates gene transcription and is associated with survival, invasion, metastases and stemness of several cancers. In the absence of WNT ligands, phosphorylated $\beta$ -
Table II. cDNA microarray analysis of Wnt/ $\beta$-catenin signalling after treatment with itraconazole.

\begin{tabular}{lccccc}
\hline Log2ratio & \multicolumn{2}{c}{ HeLa $48 \mathrm{~h}$} & & \multicolumn{2}{c}{ CaSki } \\
\cline { 2 - 3 } \cline { 5 - 6 } & $48 \mathrm{~h}$ & $96 \mathrm{~h}$ & & $48 \mathrm{~h}$ & $96 \mathrm{~h}$ \\
\hline WNT3A & -0.01 & 0.47 & & -0.13 & 0.21 \\
WNT4 & -1.86 & -0.56 & & -3.52 & -2.56 \\
WNT10A & -0.08 & 1.03 & & -3.11 & -2.07 \\
WNT inhibitor 1 & -1.99 & -2.06 & & 2.56 & 2.67 \\
WNT inhibitory factor 1 & -1.84 & -0.19 & & 0.69 & 0.04 \\
Axin-1 & 0.44 & 0.22 & & -0.8 & -0.1 \\
$\beta$-catenin & -0.02 & 0.1 & & 0.27 & -0.02 \\
TCF4 & -0.06 & 0.7 & & 0.14 & -1.76 \\
TCF7 & -0.48 & -1.25 & & 1.01 & 0.91 \\
LEF1 & 0.24 & 0.7 & & -0.41 & 0.02 \\
C-MYC & 0.42 & 0.89 & & -1.54 & -0.48 \\
Cyclin D1 & -0.02 & 0.38 & & 0.84 & 0.05 \\
\hline
\end{tabular}

In CaSki cells, itraconazole down-regulated the expression of WNT3 and WNT10A, and up-regulated that of WNT inhibitory factor-1 (WIF1). The coloured cells indicate $>4$-fold changes in transcription. LEF, Lymphoid enhancer-binding factor; TCF, T-cell factor.

catenin undergoes ubiquitination and proteasomal degradation. WNT activation leads to inhibition of the formation of the destruction complex, resulting in $\beta$-catenin stabilisation and translocation to the nucleus, where it interacts with transcription factors, such as the $\mathrm{T}$ cell factor/lymphoid enhancer-binding factor family. This leads to increased expression of oncogenic genes, such as c-MYC and cyclin D1 (CCND1).

It has been reported that WNT4 is up-regulated and associated with tumour progression in gastric cancer $(20,21)$. Moreover, in oesophageal squamous cell carcinoma, tumour invasion is associated with up-regulation of WNT10A and 


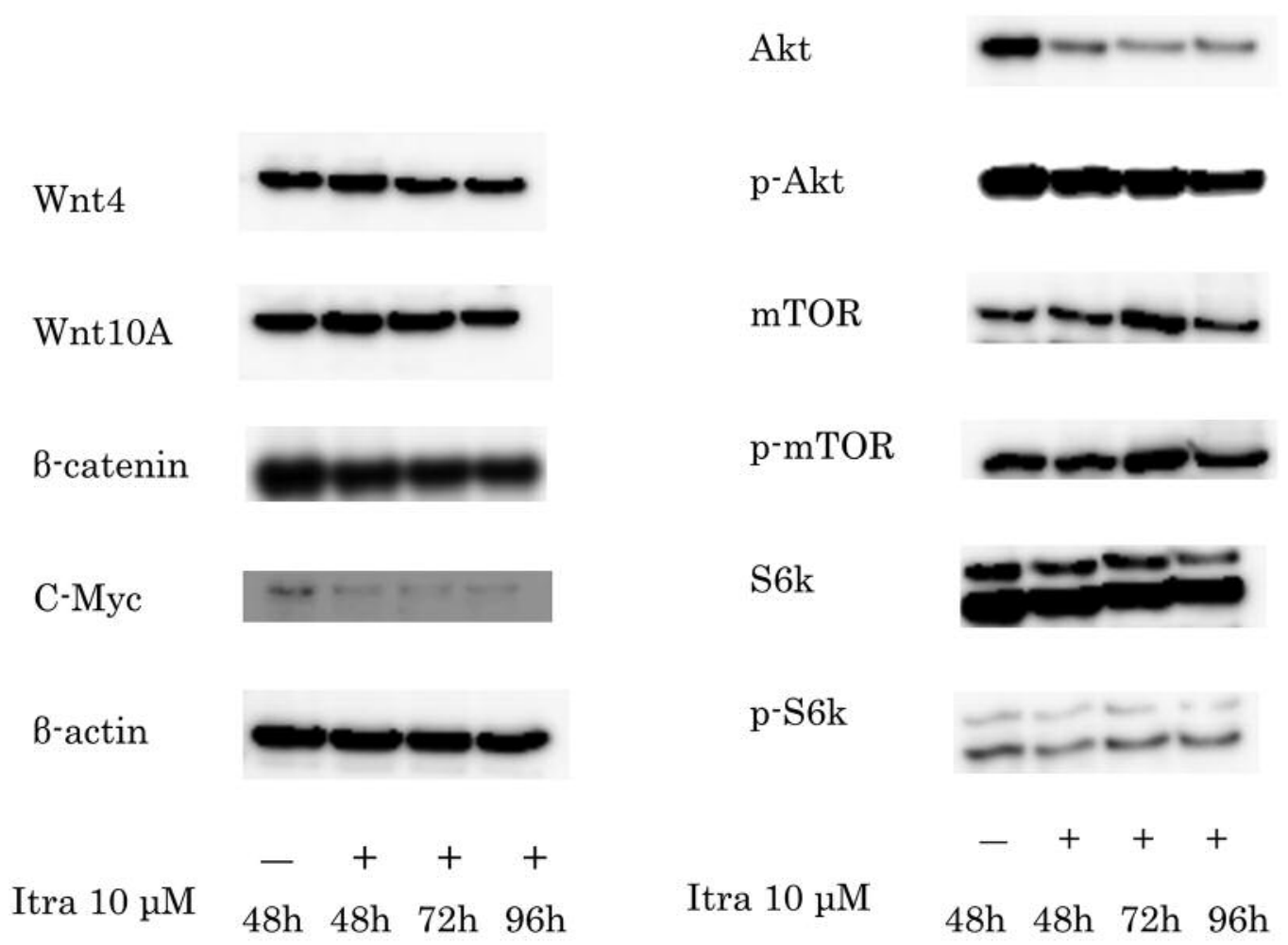

Figure 3. Western blotting of CaSki cells after treatment with itraconazole. After incubating CaSki cells with $10 \mu \mathrm{M}$ itraconazole, the expression levels of $\beta$-catenin and C-MYC proteins decreased. In addition, the phosphorylation of Akt was decreased, whereas neither that of mTOR or S6k was affected. Itra, itraconazole; mTOR, mechanistic target of rapamycin; p-S6k, phosphorylation of p70 S6 kinase; S6k, p70 S6 kinase.

down-regulation of WNT inhibitory factor-1. In addition, WNT10A induces stem-cell-like properties of self-renewal (22).

In cervical cancer, HPV E6 and E7 oncoproteins are involved in $\beta$-catenin nuclear accumulation and induce the activation of the $\mathrm{WNT} / \beta$-catenin signalling pathway $(23,24) . \beta$-Catenin expression is associated with impaired survival (25).

Furthermore, in human umbilical vein endothelial cells, itraconazole inhibits intracellular cholesterol trafficking by binding to Niemann-Pick $\mathrm{C} 1$ protein $(26,27)$. In U87 glioblastoma cells, itraconazole blocked the trafficking of cholesterol by reducing the transcription of SCP2 (28). In another study, the transcription of $A B C A 1$, which promotes cholesterol efflux across the plasma membrane, was downregulated in endometrial cancer cells, whose proliferation was unaffected by itraconazole (29). Similarly, in the present study, neither $S C P 2$ nor $A B C A 1$ was affected at the transcriptional level by itraconazole in CaSki or HeLa cells.

\section{Conclusion}

We have previously reported that itraconazole exhibited anticancer effect against endometrial cancer cells (29). Cervical and endometrial cancers are diagnosed by outpatient tissue sampling in daily practice. We are currently carryingout a window-of-opportunity clinical trial to assess the anticancer activity of itraconazole. We aim to identify relevant biomarkers in responders by obtaining tissue samples, as well as peripheral blood samples, before and after oral administration of itraconazole (UMIN000018388).

\section{Conflicts of Interest}

The Authors have no conflict of interest to declare.

\section{Acknowledgements}

This work was supported by a Japan Society for the Promotion of Science KAKENHI grant (no. JP17K11306 to Inoue K).

\section{References}

1 Global Burden of Disease Cancer Collaboration: The global burden of cancer 2013. JAMA Oncol 1: 505-527, 2015.

2 Tewari KS, Sill MW, Long HJ 3rd, Penson RT, Huang H, Ramondetta LM, Landrum LM, Oaknin A, Reid TJ, Leitao MM, Michael HE and Monk BJ: Improved survival with bevacizumab in advanced cervical cancer. N Engl J Med 370: 734-743, 2014. 
3 Tsubamoto H, Ueda T, Inoue K, Sakata K, Shibahara H and Sonoda T: Repurposing itraconazole as an anti-cancer agent: A review. Oncol Lett, 2017, in press.

4 Iida N, Takara K, Ohmoto N, Nakamura T, Kimura T, Wada A, Hirai M, Sakaeda $\mathrm{T}$ and Okumura K: Reversal effects of antifungal drugs on multidrug resistance in MDR1-overexpressing HeLa cells. Biol Pharm Bull 24: 1032-1036, 2001.

5 Shirakawa K, Takara K, Tanigawara Y, Aoyama N, Kasuga M, Komada F, Sakaeda T and Okumura K: Interaction of docetaxel ("Taxotere") with human P-glycoprotein. Jpn J Cancer Res 90: 1380-1386, 1999.

6 Rovida E and Stecca B: Mitogen-activated protein kinases and Hedgehog-GLI signaling in cancer: A crosstalk providing therapeutic opportunities? Semin Cancer Biol 35: 154-167, 2015.

7 Chakraborty C, Dutta S, Mukherjee N, Samadder S, Roychowdhury A, Roy A, Mondal RK, Basu P, Roychoudhury $\mathrm{S}$ and Panda CK: Inactivation of PTCH1 is associated with the development of cervical carcinoma: Clinical and prognostic implication. Tumour Biol 36: 1143-1154, 2015.

8 Chaudary N, Pintilie M, Hedley D, Fyles AW, Milosevic M, Clarke B, Hill RP and Mackay H: Hedgehog pathway signaling in cervical carcinoma and outcome after chemoradiation. Cancer 118: 3105-3115, 2012.

9 Xuan YH, Jung HS, Choi YL, Shin YK, Kim HJ, Kim KH, Kim WJ, Lee YJ and Kim SH: Enhanced expression of hedgehog signaling molecules in squamous cell carcinoma of uterine cervix and its precursor lesions. Mod Pathol 19: 1139-1147, 2006.

10 Chen H, Wang J, Yang H, Chen D and Li P: Association between FOXM1 and hedgehog signaling pathway in human cervical carcinoma by tissue microarray analysis. Oncol Lett 12: 26642673, 2016.

11 Samarzija I and Beard P: Hedgehog pathway regulators influence cervical cancer cell proliferation, survival and migration. Biochem Biophys Res Commun 425(1): 64-69, 2012.

12 Kim J, Tang JY, Gong R, Kim J, Lee JJ, Clemons KV, Chong CR, Chang KS, Fereshteh M, Gardner D, Reya T, Liu JO, Epstein EH, Stevens DA and Beachy PA: Itraconazole, a commonly used antifungal that inhibits Hedgehog pathway activity and cancer growth. Cancer Cell 17: 388-399, 2010.

13 Kim DJ, Kim J, Spaunhurst K, Montoya J, Khodosh R, Chandra K, Fu T, Gilliam A, Molgo M, Beachy PA and Tang JY: Openlabel, exploratory phase II trial of oral itraconazole for the treatment of basal cell carcinoma. J Clin Oncol 32: 745-751, 2014.

14 Forbes SA, Bhamra G, Bamford S, Dawson E, Kok C, Clements J, Menzies A, Teague JW, Futreal PA and Stratton MR: The catalogue of somatic mutations in cancer (COSMIC). Curr Protoc Hum Genet Chapter 10: Unit 10.11, 2008.

15 Zoncu R, Efeyan A and Sabatini DM: mTOR: from growth signal integration to cancer, diabetes and ageing. Nat Rev Mol Cell Biol 12: 21-35, 2011.

$16 \mathrm{Ji} \mathrm{J}$ and Zheng PS: Activation of mTOR signaling pathway contributes to survival of cervical cancer cells. Gynecol Oncol 117: 103-108, 2010.

17 Kim MK, Kim TJ, Sung CO, Choi CH, Lee JW, Kim BG and Bae DS: High expression of mTOR is associated with radiation resistance in cervical cancer. J Gynecol Oncol 21: 181-185, 2010.
18 Cancer Genome Atlas Research Network: Integrated genomic and molecular characterization of cervical cancer. Nature 543: 378-384, 2017.

19 Tinker AV, Ellard S, Welch S, Moens F, Allo G, Tsao MS, Squire J, Tu D, Eisenhauer EA and MacKay H: Phase II study of temsirolimus (CCI-779) in women with recurrent, unresectable, locally advanced or metastatic carcinoma of the cervix. A trial of the NCIC Clinical Trials Group (NCIC CTG IND 199). Gynecol Oncol 130: 269-274, 2013.

20 Zhu Y, Zhang B, Gong A, Fu H, Zhang X, Shi H, Sun Y, Wu L, Pan Z, Mao F, Zhu W, Qian H and Xu W: Anti-cancer drug 3,3'diindolylmethane activates Wnt4 signaling to enhance gastric cancer cell stemness and tumorigenesis. Oncotarget 7: 1631116324, 2016.

21 Volkomorov V, Grigoryeva E, Krasnov G, Litviakov N, Tsyganov M, Karbyshev M, Zavyalova M, Afanasyev S, Cherdyntseva N, Lisitsyn N and Beresten S: Search for potential gastric cancer markers using miRNA databases and gene expression analysis. Exp Oncol 35: 2-7, 2013.

22 Long A, Giroux V, Whelan KA, Hamilton KE, Tétreault MP, Tanaka K, Lee JS, Klein-Szanto AJ, Nakagawa H and Rustgi AK: WNT10A promotes an invasive and self-renewing phenotype in esophageal squamous cell carcinoma. Carcinogenesis 36: 598-606, 2015.

23 Bello JOM, Nieva LO, Paredes AC, Gonzalez AMF, Zavaleta LR and Lizano M: Regulation of the Wnt/ $\beta$-catenin signaling pathway by human papillomavirus E6 and E7 oncoproteins. Viruses 7: 4734-4755, 2015.

24 Qiang R, Cai N, Wang X, Wang L, Cui K, Wang X and Li X: MLL1 promotes cervical carcinoma cell tumorigenesis and metastasis through interaction with $\beta$-catenin. Onco Targets Ther 9: 6631-6640, 2016.

25 Liang J, Zhou H, Peng Y, Xie X, Li R, Liu Y, Xie Q and Lin Z: $\beta$-Catenin expression negatively correlates with WIF1 and predicts poor clinical outcomes in patients with cervical cancer. Biomed Res Int 2016: 4923903, 2016.

26 Chong CR, Xu J, Lu J, Bhat S, Sullivan DJ Jr and Liu JO: Inhibition of angiogenesis by the antifungal drug itraconazole. ACS Chem Biol 2: 263-270, 2007.

27 Head SA, Shi WQ, Yang EJ, Nacev BA, Hong SY, Pasunooti KK, Li RJ, Shim JS and Liu JO: Simultaneous targeting of NPC1 and VDAC1 by itraconazole leads to synergistic inhibition of mTOR signaling and angiogenesis. ACS Chem Biol 12: 174182, 2017.

28 Liu R, Li J, Zhang T, Zou L, Chen Y, Wang K, Lei Y, Yuan K, Li Y, Lan J, Cheng L, Xie N, Xiang R, Nice EC, Huang C and Wei Y: Itraconazole suppresses the growth of glioblastoma through induction of autophagy: involvement of abnormal cholesterol trafficking. Autophagy 10: 1241-1255, 2014.

29 Tsubamoto H, Inoue K, Sakata K, Ueda T, Takeyama R, Shibahara $\mathrm{H}$ and Sonoda $\mathrm{T}$ : Itraconazole inhibits Akt/mTOR signalling and proliferation in endometrial cancer cells. Anticancer Res 37: 515-519, 2017.

Received May 6, 2017

Revised May 18, 2017

Accepted May 19, 2017 